GRASAS Y ACEITES 69 (1)

January-March 2018, e240

ISSN-L: 0017-3495

https://doi.org/10.3989/gya.0884171

\title{
Evaluation of the oxidative stability of Chipotle chili (Capsicum annuum L.) oleoresins in avocado oil
}

\author{
L. Cerecedo-Cruz ${ }^{a}$, E. Azuara-Nieto ${ }^{a}$, A.J. Hernández-Álvarez ${ }^{b}$, C.R. González-González ${ }^{\mathrm{c}}$ \\ and G. Melgar-Lalanne ${ }^{\mathrm{a}, \bigotimes}$ \\ ${ }^{a}$ Instituto de Ciencias Básicas. Universidad Veracruzana. Av. Dr. Luis Castelazo Ayala s/n. Col Industrial Ánimas, 91192. Xalapa, \\ Veracruz, Mexico. \\ ${ }^{\mathrm{b}}$ Food Research and Development Center, Agriculture and Agri-Food Canada, 3600 Casavant West, St. Hyacinthe, Quebec, Canada \\ $\mathrm{J} 2 \mathrm{~S} 8 \mathrm{E} 3$. \\ 'Instituto Tecnológico Superior de Acayucan. Carretera Costera del Golfo Km 216.4 Colonia Agrícola Michapa, CP. 96100. \\ Acayucan, Veracruz, Mexico. \\ ${ }^{\square}$ Corresponding author: gmelgar@uv.mx
}

Submitted: 03 August 2017; Accepted: 30 November 2017

SUMMARY: Capsicum annuum L. (Chipotle chili) is a natural source of bioactive metabolites with antioxidant properties. The objective of this research was to obtain and characterize the oxidative stability under storage of Chipotle chili oleoresins extracted with cold-pressed avocado oil. The most efficient conditions obtained to extract carotenoids and phenolic compounds were at 1:3 ratio (chipotle chili: avocado oil; w:v) at room temperature in darkness during $48 \mathrm{~h}$. At the end of the harshest conditions $\left(45^{\circ} \mathrm{C}, 30\right.$ days), the extracts were stable to lipid oxidation with a final Totox value of 27.34 , a carotenoid preservation of $85.6 \%$, antioxidant activity retention of $80.66 \%$ and a color change $(\Delta \mathrm{E})$ of 1.783 . The kinetic constants obtained were higher for peroxide formation than for carotenoid degradation. The oleoresins obtained could be considered an economic and sustainable alternative to extract carotenoids with good oxidation stability that could be used in foodstuffs.

KEYWORDS: Capsicum annum L.; Carotenoids; Lipid stability; Oleoresin

RESUMEN: Evaluación de la estabilidad oxidativa de oleorresinas de chile Chipotle (Capsicum annuum L.) en aceite de aguacate. Capsicum annuum L. (chile Chipotle) es una fuente natural de metabolitos bioactivos. El objetivo de esta investigación consistió en evaluar la estabilidad oxidativa durante el almacenamiento de aceites de aguacate extraído en frio en presencia de oleorresinas de Chile Chipotle. Las condiciones más eficientes obtenidas para la extracción de carotenoides se dieron a una concentración 1:3 (p/v: chipotle chile/aceite de aguacate) durante $48 \mathrm{~h}$ en oscuridad a temperatura ambiente. Al final de las condiciones de almacenamiento más severas $\left(45^{\circ} \mathrm{C}, 30\right.$ días) los extractos fueron estables a la oxidación lipídica con un valor de Totox de 27.34, una conservación de carotenoides del $85.6 \%$, una retención de la actividad antioxidante del $80.66 \%$ y un cambio de color $(\Delta \mathrm{E})$ de 1.783. Las constantes cinéticas obtenidas fueron mayores para la formación de peróxidos que en la degradación de carotenoides. En conclusión, las oleorresinas obtenidas bajo las condiciones anteriores pueden considerarse como una alternativa económica y sustentable para la extracción de carotenoides con una buena estabilidad oxidativa.

PALABRAS CLAVE: Capsicum annum L.; Carotenoides; Estabilidad oxidativa; Oleorresinas

ORCID ID: Cerecedo-Cruz L https://orcid.org/0000-0003-4057-1310, Azuara-Nieto E https://orcid.org/0000-00021290-2787, Hernández-Álvarez AJ https://orcid.org/0000-0003-4154-8630, González-González CR https://orcid. org/0000-0002-5837-4895, Melgar-Lalanne G https://orcid.org/0000-0002-7854-1232

Citation/Cómo citar este artículo: Cerecedo-Cruz L, Azuara-Nieto E, Hernández-Álvarez AJ, González-González CR, Melgar-Lalanne G. 2108. Evaluation of the oxidative stability of Chipotle chili (Capsicum annuum L.) oleoresins in avocado oil. Grasas Aceites 69 (1), e240. https://doi.org/10.3989/gya.0884171

Copyright: (C2018 CSIC. This is an open-access article distributed under the terms of the Creative Commons Attribution 4.0 International (CC BY 4.0) License. 


\section{INTRODUCTION}

Adding additives is a common practice in food processing to avoid spoilage, food alterations and to improve some sensorial characteristics in an economical and competitive way. However, nowadays, consumers are concerned about the safety of additives (Bearth et al., 2014). Therefore, the food industry is migrating to develop safer additives, usually extracted from natural sources capable of providing preservative functions in addition to sensorial characteristics (Melgar-Lalanne et al., 2016).

Chipotle chili (Capsicum annuum L.) is a medium pungency smoke-dyed Jalapeño chili widely appreciated for its unique flavor in the preparation of marinated sauces, purees, canned products, snacks and as an ingredient in traditional Mexican cuisine (Gómez-Moriel et al., 2012). Although their sensorial characteristics remain as the main reason for their industrial and domestic use, the high quantity and quality of the antioxidants present in this fruit make them an outstanding natural antioxidant. This high antioxidant capacity is provided by bioactive metabolites such as phenolic compounds, capsaicinoids and carotenoids where the hydrophilic fraction of these compounds is the main contributor to the total antioxidant activity of the fruit (Kittisakulam et al., 2016). However, when extracted in non-polar solvents, only a small portion of the hydrophilic phenolic compounds could be extracted while the lipophilic fraction is extracted in its majority (Guadarrama-Lezama et al., 2012; Cavazza et al., 2015). These non-polar extracts are usually obtained with organic solvents which require them to be removed before their addition to foods (Guadarrama-Lezama et al., 2012). Moreover, the high process temperatures $\left(>60{ }^{\circ} \mathrm{C}\right)$ during industrial processing may produce structural changes in some valuable compounds leading to a possible loss in functionality (Melgar-Lalanne et al., 2016).

Carotenoids, which are important both as colorants and antioxidants, are hydrophobic extracted compounds that belong to the family of terpenoids with a wide range of organic solvents such as hexane, acetone and methanol with different extraction rates (Melgar-Lalanne et al., 2016). Recently, the use of vegetable oils as non-polar solvents has been explored with a relatively good extraction rate to extract lipophilic metabolites in different matrixes (Goula et al., 2017; Guadarrama-Lezama et al., 2012). Their low polarity (between $5-15 \mathrm{mN} / \mathrm{m}$ ) (Kovacs et al., 2016) and high bio-accessibility of carotenoids in vegetable oils (Victoria-Campos et al., 2013; Unlu et al., 2005) makes them an economic and sustainable option. Although few studies have used vegetable oils to extract Capsicum bioactive metabolites (Guadarrama-Lezama et al., 2012; Amruthraj et al., 2014), carotenoids have been successfully extracted in edible oils from other sources such as shrimp waste and pomegranates (Sachindra and Mahendrakar, 2005; Goula et al., 2017). Moreover, the presence of carotenoids was responsible for preventing oxygen degradation in olive oil during storage (Cavazza et al., 2015; Salazar et al., 2012).

Cold-pressed avocado oil is extracted similarly to extra virgin olive oil and appreciated for culinary purposes, for its potential health benefits and for being environmentally friendly (Wong et al., 2011). It contains mainly oleic acid $(69-74 \%)$ as well as a small minority of desirable compounds like vitamins, phytosterols, chlorophylls and carotenes that play a positive role in reducing coronary heart disease risk, cataracts and diabetes (Sun-Waterhouse et al., 2011a). Avocado oil was able to increase the in vivo absorption of carotenoids in in vivo trials (Unlu et al., 2005). From a technological point of view, cold-pressed avocado oil (also cold virgin avocado oil) is a high quality oil, rich in oleic acid, extracted without the presence of organic solvents and without the addition of artificial antioxidants which improves its shelf life in a eco-friendly way. These characteristics allow cold-pressed avocado oil (similarly to extra-virgin olive oil) to be a suitable model to study the lipid oxidation of oils and fats when a substance with proven antioxidant properties is added (Wong et al., 2011).

In this scenario, the use of avocado oil as solvent may offer an attractive advantage compared to conventional methods for carotenoid extraction due to its low polarity, high accessibility, oxidative stability and safety. Furthermore, being that it is a coldpressed oil there are no traces of organic solvents in the oleoresin composition (Güneser et al., 2017).

The objective of this research was to explore the oxidative stability under storage of Chipotle chili (C. annuum L.) oleoresins extracted with commercial cold-pressed avocado oil.

\section{MATERIALS AND METHODS}

\subsection{Materials}

Chipotle chili fruits (Capsicum annuum L.) and cold-pressed avocado oil (Ahuacatlán, Mexico) were bought in a supermarket in Xalapa, Veracruz (Mexico). Only whole and free of damage Chipotle fruits were considered for this research. All chemicals used were purchased from Sigma-Adrich (USA), Merk (Germany), or Dibico (Mexico) and were of analytical grade.

\subsection{Chipotle chili oleoresins preparation}

Due to the high relative humidity in Xalapa, Ver. Mex. (around 78\% annual, Conagua http://200.4.8.21/observatorios/historica/veracruz.pdf, reviewed on Nov, 17, 2017), and although 
Chipotle chili is a sun dried chili, the fruits were previously conditioned at $45^{\circ} \mathrm{C}$ in order to reduce the water content until constant weight $(48-72 \mathrm{~h}$ ) and facilitate grinding. The initial moisture content of commercial chipotle chili was $33.97 \pm 0.14$ $\mathrm{gH}_{2} 0 / 100 \mathrm{~g}$ sample; and after the conditioning at 45 ${ }^{\circ} \mathrm{C}$ the water content was $20.81 \pm 0.51 \mathrm{gH}_{2} 0 / 100 \mathrm{~g}$ sample. Then, the chilies were ground in a commercial mill (Hamilton Beach, EUA), and subsequently sieved using a $1 \mathrm{~mm}$ mesh. Milled chili was mixed with avocado oil in two different ratios: 1:2 and 1:3 (w/v: Chipotle chili/avocado oil) and conserved in amber glass bottles in the dark for $48 \mathrm{~h}$ at room temperature $\left(\sim 25^{\circ} \mathrm{C}\right)$. The oleoresins were centrifuged $\left(3,500 \mathrm{~g}, 15 \mathrm{~min}, 4^{\circ} \mathrm{C}\right)$ to facilitate solid separation, decanted, filtered and stored in amber glass bottles protected from light at $4^{\circ} \mathrm{C}$ until further use.

The total carotenoids and total phenolic compounds extraction yield (\%) were calculated as equation (1):

$$
\text { Extraction Yield }(\%)=\frac{\left[A_{\text {oil }}-A_{\text {avocado }}\right]}{\left[A_{\text {chili }}\right]} \times 100 \quad \text { Eq. (1) }
$$

Where: $\mathrm{A}_{\text {oil }}$ is the total carotenoid or total phenolic compound concentration in the oleoresin $(\mu \mathrm{g} / \mathrm{mL})$; $\mathrm{A}_{\text {avocado }}$ is the total carotenoid or total phenolic compound concentration in the avocado oil and $\mathrm{A}_{\text {chili }}$ is the total carotenoid or total phenolic compound concentration of chili powder $(\mu \mathrm{g} / \mathrm{mL})$.

\subsection{Total carotenoid content determination}

The total carotenoid content was determined (Hornero-Méndez and Mínguez-Mosquera, 2001). Briefly, $100 \mu \mathrm{L}$ of Chipotle oleoresin $(-120 \mu \mathrm{g})$ were diluted with $25 \mathrm{~mL}$ of acetone and mixed in the dark to avoid oxidation. Then, $1 \mathrm{~mL}$ of each sample was read with a spectrophotometer (Velab VE-5600UV, Mexico City, Mexico) at 472 and 508 $\mathrm{nm}$ with acetone as blank. Total carotenoids were expressed following the Lambert-Beer law with the following equations (2)-(4).

$C R=\frac{2144.0 \times A_{508-} 403.3 \times A_{472}}{270.9}$

$C Y=\frac{1724.3 \times A_{472-} 2450.1 \times A_{508}}{270.9}$

$C T=C R+C Y$

Where: $\mathrm{CR}$ is the red carotenoid fraction; $\mathrm{CY}$ is the yellow carotenoid fraction and $\mathrm{CT}$ is the total carotenoids; $\mathrm{A}_{508}$ and $\mathrm{A}_{472}$ is the read absorbance at these wavelengths expressed in $\mathrm{nm}$.

\subsection{Determination of total phenolic compounds}

Total phenolic compounds were determined by the Folin test as described by Guadarrama-Lezama et al., 2012 using the Folin-Ciocalteau reagent. The Folin-Ciocalteu reagent was diluted in deionized water 1:10 (w/w) prior to use. Each sample was diluted 1:5 (w/w) with ethanol, and a $0.1 \mathrm{~mL}$ aliquot was mixed with $0.75 \mathrm{~mL}$ of the previously prepared Folin-Ciocalteau reagent. The solution was incubated at room temperature for $5 \mathrm{~min}$ and $0.75 \mathrm{~mL}$ of sodium bicarbonate $(60 \mathrm{~g} / \mathrm{L})$ were added and thoroughly mixed. The mixture was incubated at room temperature for $90 \mathrm{~min}$ and filtered by using a 0.45 $\mu \mathrm{m}$ syringe filter (Whatman, International Ltd., Maidstone, Kent, UK). Absorbance was measured at $750 \mathrm{~nm}$. Gallic acid was used as standard. Results were expressed as gallic acid equivalents $(\mu \mathrm{g})$ per $\mathrm{mL}$ of oleoresin.

\subsection{Antioxidant activity}

\subsubsection{Ferric reduction antioxidant power (FRAP)}

FRAP was determined as described by Benzie and Strain (1996) with slight modifications. FRAP reagent was prepared as follows: $0.3 \mathrm{M}$ acetate buffer (pH 3.6), $10 \mathrm{mM}$ TPTZ-HCl (2,4,6-Tripyridyls-Triazine: $\mathrm{HCl} 40 \mathrm{mM}$ ), and $20 \mathrm{mM}$ ferric chloride 10:1:1 (v:v:v) were heated at $37^{\circ} \mathrm{C}$ for $30 \mathrm{~min}$. Then, $100 \mu \mathrm{L}$ of samples were diluted with $1 \mathrm{~mL}$ of acetone. Absorbance was measured as $593 \mathrm{~nm}$ and TEAC (trolox equivalent antioxidant capacity) was expressed in milimoles $(\mathrm{mM})$ of TEAC/g. A standard curve of trolox (6-hydroxy-2,5,7,8-tetramethylchloroman-2-carboxulic acid) was used to estimate the antioxidant capacity of the samples.

\subsubsection{Scavenging of $\mathrm{ABTS}^{+}$radical}

The scavenging activity of $\mathrm{ABTS}^{+}$radical was determined as described by Sousa et al., (2015) based on the capacity of a sample to inhibit the $\mathrm{ABTS}^{+}$radical produced by reacting $7 \mathrm{mM}$ ABTS stock solution with $2.45 \mathrm{mM}$ PotasiumPersulfate $\left(\mathrm{K}_{2} \mathrm{~S}_{2} \mathrm{O}_{7}\right)$ and allowing it to stand in the dark at room temperature for $12-16 \mathrm{~h}$ before use. The stock solution of $\mathrm{ABTS}^{+}$was diluted in ethanol until an absorbance of $0.70 \pm 0.02$ at $734 \mathrm{~nm}$ at $25^{\circ} \mathrm{C}$. Once the radical was formed, $2.9 \mathrm{~mL}$ of the $\mathrm{ABTS}^{+}$radical solution was mixed with $100 \mu \mathrm{L}$ of each sample and the absorbance measured at $734 \mathrm{~nm}$. A calibration curve was prepared with Trolox diluted in ethanol at 10, 20, 30, 40, 50, 60, 70, 80, 90 and $100 \mathrm{mM}$ and read at $734 \mathrm{~nm}$. Inhibition (\%) was calculated as Equation (5): 


$$
\% \text { inhibition }=\frac{A_{s t 0}-A_{s t f}}{A_{s t 0}-\left(\frac{A_{s d 0}-A_{s d f}}{A_{s d 0}}\right)}
$$

Where $\mathrm{A}_{\text {sto }}$ and $\mathrm{A}_{\text {stf }}$ are the initial and final absorbance; $\mathrm{A}_{\mathrm{dto}}$ and $\mathrm{A}_{\mathrm{dtf}}$ are the initial and final absorbance of the dissolvent. The results were expressed as $\mu \mathrm{M}$ trolox / g.

\subsection{Color measurement}

Color measurements of chili oleoresins were carried out using a colorimeter (Color Flex XC1115 Hunter Lab, USA). The instrument was calibrated with a tile $\left(L^{*}=97.02, a^{*}=0.08, b^{*}=1.75\right)$ before the measurements and expressed in the CIELab color model. At least 10 measurements of each sample were taken and average values were determined for further calculation. Color changes can be measured as the modulus of the distance vector between the initial color values and the actual color coordinated. This concept is named "total color difference" (Pathare et al., 2013) and is calculated in the CIELab color model as Equation (6).

$$
\Delta E=\sqrt{\left(\Delta L^{*}\right)^{2}+\left(\Delta a^{*}\right)^{2}+\left(\Delta b^{*}\right)^{2}}
$$

Where $L^{*}$ value is the measurement of lightness, ranging from 0 (black) to 100 (white); $a^{*}$ value ranges from -100 (green) to +100 (red); $b^{*}$ value ranges from -100 (blue) to +100 (yellow); $\Delta \mathrm{L}^{*}, \Delta \mathrm{a}^{*}$, $\Delta \mathrm{b}^{*}$ are the absolute differences between the initial and final values. $\Delta \mathrm{E}$ is the total difference between the reference and sample color. Differences in color were classified as very distinct $(\Delta E>3)$, distinct $(1.5<\Delta E<3)$ and small difference $(\Delta E<1.5)$ as according to Pathare et al., 2013.

In addition, a more appropriate measurement of color was obtained from the calculation Chroma (Eq.7) and hue angle (Eq.8). Hue angle is the degree to which a stimulus can be described as similar to or different from stimuli that are described as red, green, blue and yellow. So the higher the hue angle is, the less yellow. Chroma is an index somewhat analogous to color saturation or intensity of a color. Hence, the higher Chroma value, the higher the color intensity. Both parameters are polar coordinates and easy to visualize, giving a more reliable appreciation of color.

$$
\text { Chroma }=\sqrt{\left(a^{2}+b^{2}\right)}
$$

Hue angle $=\arctan \left(\frac{b}{a}\right)$

\subsection{Degradation under storage conditions}

Chipotle chili oleoresin in avocado oil at 1:2 (CHOAO 1:2) (w/v) and Chipotle chili oleoresin in avocado oil 1:3 (CHOAO 1:3) (w/v) and avocado oil (AO) (as control) were exposed to three different temperatures under darkness $(8,25$ and 45 ${ }^{\circ} \mathrm{C}$ ) and stored for 28 days. Darkness was carried out to guarantee that the oxidation was only due to the temperature and not to light (photo-oxidation); temperatures were determined in function of refrigeration conditions $\left(8{ }^{\circ} \mathrm{C}\right)$, room temperature $\left(25^{\circ} \mathrm{C}\right)$ and accelerated oxidation conditions along with extreme environmental temperatures in tropical zones $\left(45^{\circ} \mathrm{C}\right) ; 28$ days of storage was considered since it was a sufficient lapse of time to observe the degradation of the components analyzed. A chemical analysis were done each third day. Degradation was calculated as a percentage the difference between the metabolite (total carotenoids or total phenolic compounds) at a determined time and at initial time.

\subsection{Peroxide, $p$-anisidine and Totox values}

Peroxide value (PV), $p$-anisidine value (AV) and Totox values were determined. PV was evaluated following the AOCS official method (Cd 8-53) and was expressed as peroxide miliequivalents of active oxygen per kilogram of oil $\left(\mathrm{meqO}_{2} / \mathrm{kg}\right)$. An aliquot $(0.5 \mathrm{~g})$ of oil was used for each assay. A blank sample as reagent control was used and carried through all the steps. AV was determined with the AOCS official method (Cd 8-53) and expressed as $\mathrm{mg} / \mathrm{kg}$, an aliquot $(0.5 \mathrm{~g})$ of oil was used for each assay and the sample's absorbance was measured at $350 \mathrm{~nm}$ (AOCS, 2000). The Totox value (a total oxidation value) gives an overall and empirical measurement of the relevant precursors, the non-volatile carbonyls, present in the oils (Wei et al., 2009) and was calculated with Equation. (9).

Totox value $=2 P V+A V$

\subsection{Kinetics considerations for total carotenoid degradation and peroxide formation}

The total carotenoid degradation and peroxide formation due to storage were assumed to follow first order kinetics (Equation. (10) as Vikram et al., 2005.

$\pm \frac{d C}{d t}=k C$

Where $\mathrm{C}$ is the total carotenoids or peroxide index present in the oleoresin at time $t ; t$ is the storage time; and $k$ is the kinetic constant for carotenoid 
degradation or peroxide formation, $C_{0}$ is the carotenoid concentration or peroxide index at initial time, so the linear relationship for Equation (11) is:

$\ln C=\ln C_{0} \pm k t$

For equations (10) and (11) the plus sign (+) is applied to peroxide formation and the minus sign (-) for carotenoid degradation.

The kinetic constant $(k)$ was assumed to vary with the absolute temperature (T), according to the Arrhenius-type equation:

$k=K_{0} \exp \left(\frac{-E_{a}}{R T}\right)$

Where $K_{0}$ is the frequency factor $\left(\right.$ weeks $\left.^{-1}\right)$, Ea is the activation energy $(\mathrm{kJ} / \mathrm{mol}), \mathrm{R}$ is the gas constant $(8.314 \mathrm{~J} / \mathrm{molK})$ and $\mathrm{T}$ is the absolute temperature $(\mathrm{K})$.

\subsection{Statistical analysis}

Experimental data for the different parameters were fitted and processed with Excel 7 (Microsoft, Redmond, WA, USA) and Sigma Plot 11.0 software (SPSS Inc, Chicago, Il, USA). All results were expressed as mean values of triplicates. Statistical comparisons between two groups were made using the Student's test. With several groups, one-way analysis of variance was used. When significant $\mathrm{F}$ values were obtained, group differences were evaluated by the Tukey test. The significant level considered was $\mathrm{p}<0.05$.

\section{RESULTS AND DISCUSSION}

\subsection{Extraction of total carotenoids and total phenolic compounds and color parameters}

The data of the initial total carotenoids, phenolic amount and color parameters of chipotle chili powder, avocado oil, CHOAO 1:2 and CHOAO 1:3 are shown in table 1 . The best extraction of total carotenoids and total phenolic compounds as well as the main antioxidant activity was obtained with CHOAO 1:3. In this oleoresin, the total carotenoid extraction rate was $40.08 \%(\mathrm{w} / \mathrm{v})$ and the total phenolic extraction rate $2.26 \%$ (Table 1 ), however, CHOAO 1:3 was more diluted than CHOAO 1.2. CHOAO 1:2 had significantly $(\mathrm{p} \leq 0.05)$ higher antioxidant activity than CHOAO 1:3 (Figure 1c). This could be attributed to the higher total content of carotenoids as well as phenolic compounds presents in CHOAO 1:2 when expressed in oil $\mathrm{ml}(408.86$ $\mu \mathrm{g}$ carotenoids/ $\mathrm{mL}$ oil in CHAOA 1:2 vs. 309.84 $\mu \mathrm{g}$ carotenoids/ $\mathrm{mL}$ oil in CHOAO 1:3). The tested sample of avocado oil showed a similar composition

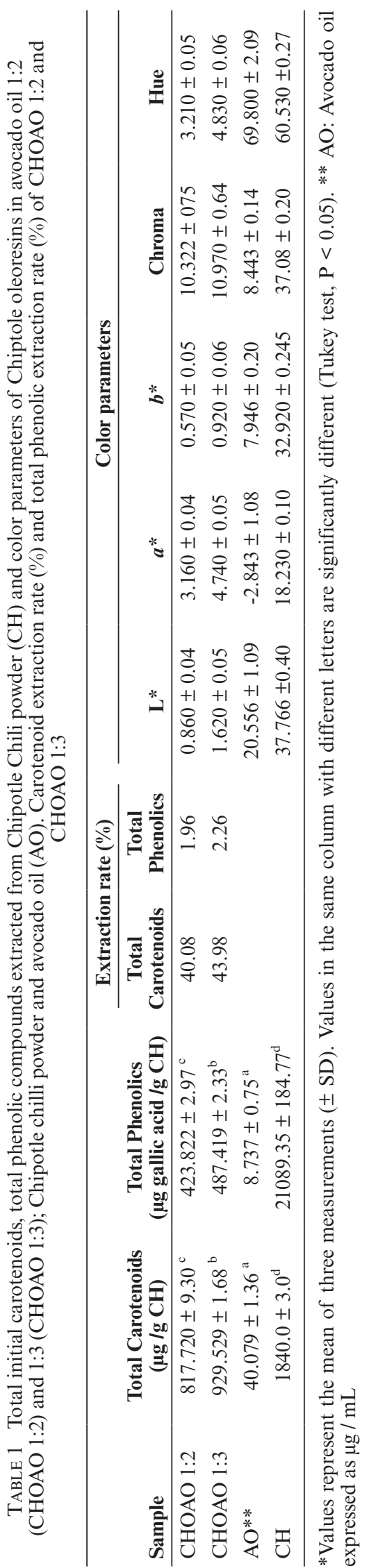

Grasas Aceites 69 (1), January-March 2018, e240. ISSN-L: 0017-3495 https://doi.org/10.3989/gya.0884171 
(a)

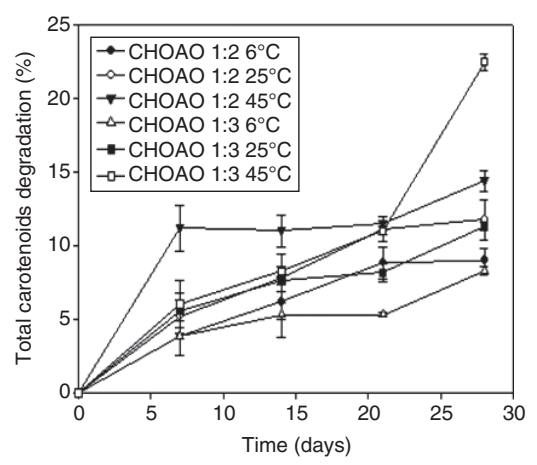

(b)

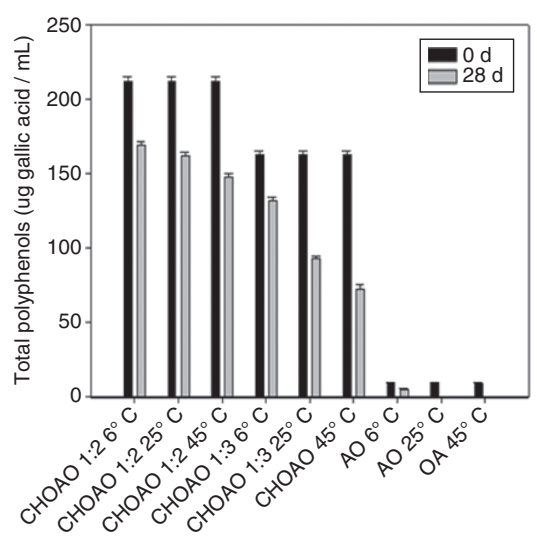

(c)

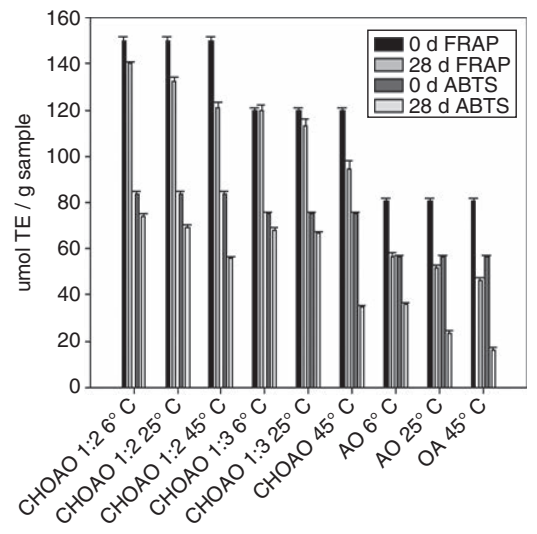

FIGURE 1. Effect of temperature and storage time on degradation of a) Total carotenoids expressed as difference between final and initial carotenoids; b) Total phenolic compounds; c) Antioxidant activity expressed as $\mu \mathrm{mol} \mathrm{TE} / \mathrm{g}$ sample of Chipotle oleoresin in avocado oil 1:2 (CHOAO 1:2), Chipotle oleoresin in avocado oil 1:3 (CHOAO 1:3) and avocado oil (AO).

to the one previously reported (Qin and Zhong, 2016). However, it was poor in carotenoids and phenolic compounds when compared with the oleoresin obtained.

The carotenoids extracted in the present research with avocado oil were higher $(929.529 \pm 1.68 \mu \mathrm{g} / \mathrm{g}$ Chipotle powder; CHOAO 1:3) than previous reports using maceration with other vegetable oils. So, Guadarrama-Lezama et al., 2012 obtained up to $231.1 \mu \mathrm{g}$ Carotenoids /mL oil in Capsicum annuum L. grossum when extracted with corn oil at higher temperatures (between 60 and $80{ }^{\circ} \mathrm{C}$ ) and similar to those obtained with the use of supercritical $\mathrm{CO}_{2}$ and avocado oil as solvents in chili obtained up to 280 to $460 \mu \mathrm{g}$ of capsanthin /g dry matter a major carotenoid in chili (Barros et al., 2016). Differences regarding other vegetable oils are probably due to the diverse nature of the fatty acids present amongst them (Sachindra et al., 2005).

The hydrophilic nature of phenolic compounds could be responsible for their poor extraction in the present research (Asnin and Park, 2015). Hence, their presence cannot be considered as an important factor in the prevention of the lipid oxidation of oleoresins. Nonetheless, the phenolic compounds measured were slightly higher than those reported in corn oil by Guadarrama-Lezama et al., 2012 with other pungent chili and the degradation rate was lower in both oleoresins than in the avocado oil. This fact shows that the carotenoids may have a key role in oleoresin protection against oxidation.

Therefore, the color components from the chili powder, mainly red components, could be extracted from oil. Both oleoresins showed a very dark red color (almost black) as can be appreciated in Table 1 , with the most concentrated one being the darkest, as previously reported (Akbas et al., 2017).

\subsection{Lipid oxidation during storage}

Peroxides are primary oxidation products that can further undergo degradation to form low molecular weight aldehydes and ketones, hence giving an idea about the present oxidation state of oils and fats and are the main oxidation products formed during auto-oxidation. Radicals are prone to produce peroxidation and follow the typical chain reactions. Meanwhile, the anisidine determination determines the amount of aldehyde (principally 2-alkenals and 2,4-alkadienals) in fats and oils and gives evidence about the shelf life and the secondary oxidation products, mainly aldehydes and ketones. Finally, the Totox value is used to estimate the oxidative deterioration of food lipids since it includes both parameters and is an indicator of the past history of the oil (as reflected in AV) and the present state (as evidenced in PV). Subsequently, PV can decrease over time when secondary products are formed and AV and Totox values should be considered for a better interpretation of the oxidation phenomena (Shahidi and Wanasundara, 2002).

The PV and AV of CHOAO 1:2, CHOAO 1:3 and AO during storage at different temperatures $(6,25$ and $45^{\circ} \mathrm{C}$ ) are shown in Table 2 and Totox kinetics are presented in Figure 2. In avocado oil, the results of $\mathrm{PV}$ and $\mathrm{AV}$ were lower than those previously reported in avocado oils from different varieties (Prescha et al., 2014; Espinosa-Alonso et al., 2017). No references about lipid oxidation in high concentrated Capsicum oleoresins were found. However, in infused edible oils (up to 3\% of Capsicum powder or Capsicum oleoresins), the presence of the Capsicum compounds, mainly the carotenoid fraction, provided a protective effect against lipid oxidation in infused oils due to their non-polar nature (Rege and Momin, 2017, Cavazza et al., 2015; Salazar et al., 2012). 
Evaluation of the oxidative stability of Chipotle chili (Capsicum annum L.) oleoresins in avocado oil 7

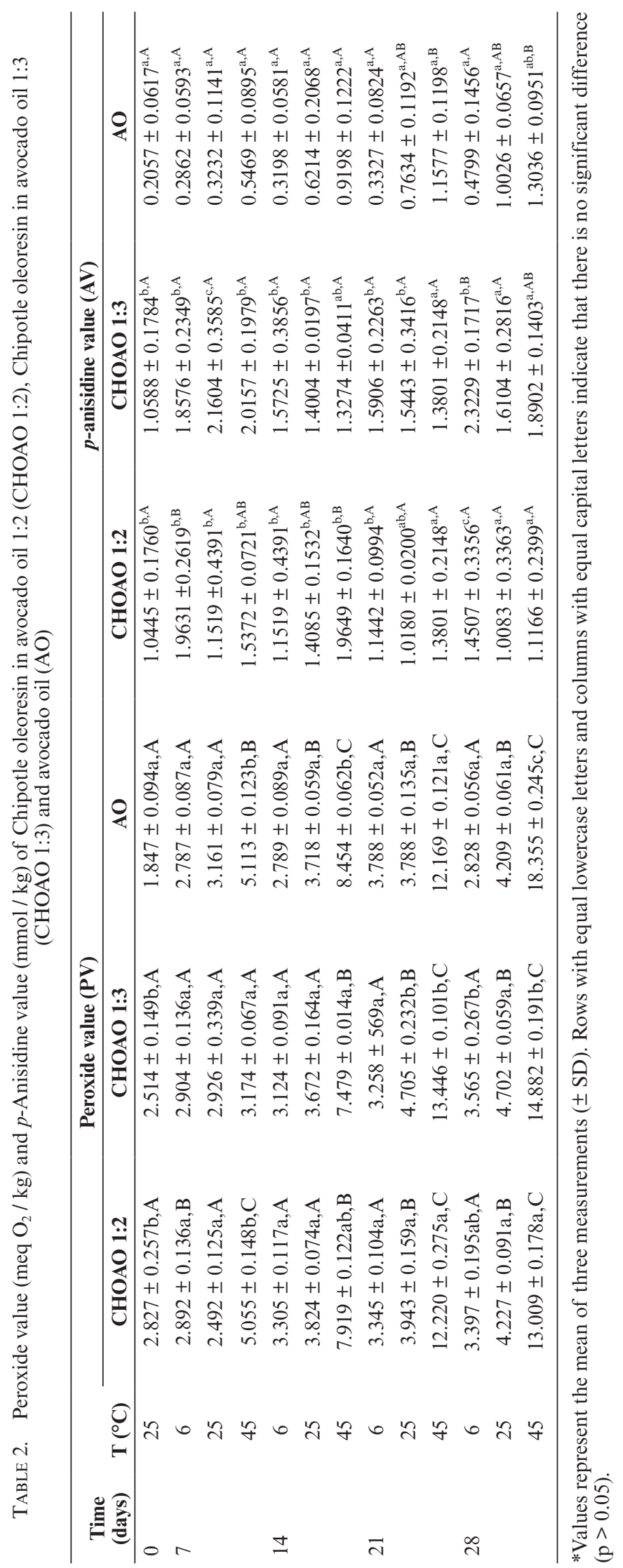


The results of the AV of avocado oil and both oleoresins are shown in Table 2. The AV value increased during all the storage times analyzed in the AO. However, the behaviors in both oleoresins were different. In CHOAO 1:2 AV increased during the first 7 days and after this period the value was reduced. Meanwhile, in CHOAO 1:3, it decreased during the first week and after that, increased during the second and third weeks. A similar behavior was observed in sardine oil when different essential oils were added as antioxidant. This behavior may be due to the presence of carotenoids and polyphenols which can suffer structural changes during the oxidation process which affect the formation of aldehydes and ketones (Vaisali et al., 2016).

In order to appropriately determine this phenomenon in edible oils, in addition to the detection of primary and secondary oxidation products, a combination of methods which measures the scavenging electron radical capacity such as ABTS and FRAP (Moon and Shibamoto, 2009; Shahidi and Zhong, 2015) as well as the degradation of antioxidant compounds (carotenoids and phenolic compounds) present was applied (Figure 1). Antioxidants can

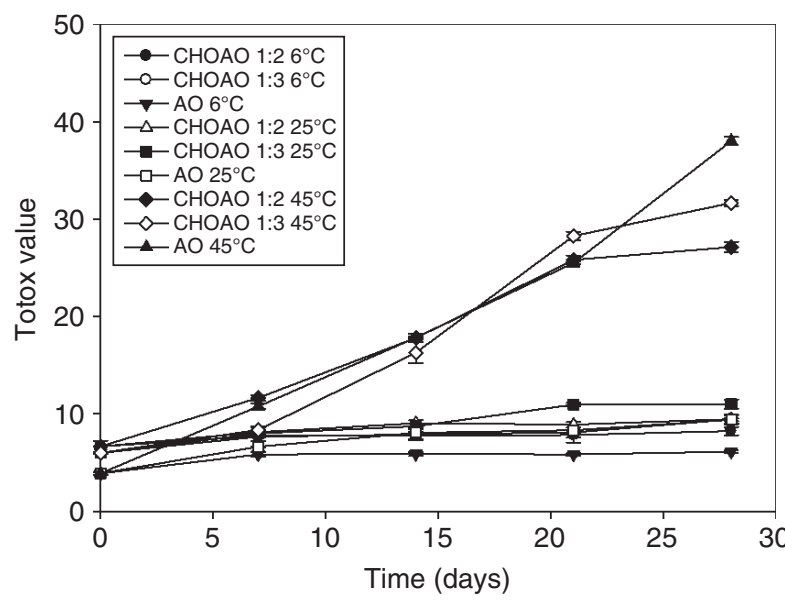

FIGURE 2. Totox value of Chipotle oleoresins in avocado oil 1:2 (CHOAO 1:2), 1:3 (CHOAO 1:3) and avocado oil (AO) at different temperatures during storage time. neutralize the radical cation $\mathrm{ABTS}^{*+}$ by direct reduction via electron donation or by radical quenching via hydrogen atom donation. The balance of these two mechanisms is determined by antioxidant structure and the $\mathrm{pH}$ of the medium (Prior et al., 2005). Hence, although the TEAC assay is usually classified as an electron transfer based method, the hydrogen atom mechanism also applies. While FRAP antioxidants are also known as reductants, their electron donating capability can not only allow the scavenging of free radicals and other oxygen derived reactive oxygen species, but also reduce higher valent elements to their lower their valence state. The redox potential or reducing power of antioxidants is an important indicator of their antioxidant efficacy. The FRAP assay is a typical electron transfer based method that measures the reduction of ferric ion $\left(\mathrm{Fe}^{3+}\right)$-ligand complex to the intensely blue colored ferrous $\left(\mathrm{Fe}^{2+}\right)$ complex by antioxidants in acidic media. Both tests showed the protective effect of the antioxidant compounds present in the Chipotle chili to avoid the rancidity of the oleoresins when compared with the avocado oil.

During the storage time, ABTS ${ }^{\circ+}$ and FRAP capacities showed similar trends; avocado oil and both oleoresins were capable of scavenging both radicals in a concentration/temperature dependent manner (Fig. 1). For all samples tested at 0 days (beginning of storage) both radical capacities were stable and showed no difference between them, with no effect from the temperature applied. Nonetheless, CHOAO 1:2 showed the best scavenging electron radical capacities with an antioxidant activity loss at the end of the storage time at 45 ${ }^{\circ} \mathrm{C}$ of $36.671 \pm 1.316 \%$ measured by $\mathrm{ABTS}^{\circ+}$ and $18.214 \pm 1.952 \%$ measured by FRAP assay. This might be due to the higher content of carotenoids and other antioxidants which reduces oxidative degradation. Furthermore, CHOAO 1:3 showed no differences $(p \leq 0.05)$ between $6{ }^{\circ} \mathrm{C}$ and $25^{\circ} \mathrm{C}$, for both capacities, suggesting a possible alternative antioxidant (AOX) resistance of the compounds contained in the oleoresin (storing temperatures which do not exceed $20-25{ }^{\circ} \mathrm{C}$ better preserve carotenoid

TABLE 3. Kinetic parameters of total carotenoid degradation and peroxide formation of Chipotle oleoresin in avocado oil 1:2 (CHOAO 1:2) and Chipotle oleoresin in avocado oil 1:3 (CHOAO 1:3) under storage at different temperatures.

\begin{tabular}{|c|c|c|c|c|c|c|c|c|c|}
\hline \multirow[b]{2}{*}{ Sample } & \multirow[b]{2}{*}{$\mathrm{T}\left({ }^{\circ} \mathrm{C}\right)$} & \multicolumn{4}{|c|}{ Carotenoid degradation } & \multicolumn{4}{|c|}{ Peroxide formation } \\
\hline & & $\begin{array}{c}k \times 10^{2} \\
\left(\text { weeks }^{-1}\right)\end{array}$ & $\mathbf{R}^{2}$ & $\underset{(\mathrm{kJ} / \mathrm{mol})}{\mathbf{E a}}$ & $\begin{array}{c}K_{0} \\
\text { (weeks }^{-1} \text { ) }\end{array}$ & $\begin{array}{c}k \times 10^{2} \\
\left(\text { weeks }^{-1}\right)\end{array}$ & $\mathbf{R}^{2}$ & $\begin{array}{c}\text { Ea } \\
(\mathrm{kJ} / \mathrm{mol})\end{array}$ & $\begin{array}{c}K_{0} \\
\text { (weeks }^{-1} \text { ) }\end{array}$ \\
\hline \multirow[t]{3}{*}{ CHOAO 1:2 } & 6 & 2.42 & 0.966 & 8.707 & 1.040 & 5.13 & 0.927 & 38.337 & 659343.55 \\
\hline & 25 & 3.14 & 0.971 & & & 9.26 & 0.941 & & \\
\hline & 45 & 3.83 & 0.961 & & & 39.35 & 0.973 & & \\
\hline \multirow[t]{3}{*}{ CHOAO 1:3 } & 6 & 1.89 & 0.949 & 20.550 & 123.53 & 8.05 & 0.947 & 34.598 & 228433.40 \\
\hline & 25 & 2.68 & 0.954 & & & 17.89 & 0.975 & & \\
\hline & 45 & 5.63 & 0.943 & & & 50.24 & 0.971 & & \\
\hline
\end{tabular}


stability, therefore safeguarding the nutritional value) (Hidalgo et al., 2008). At $45^{\circ} \mathrm{C}$ the antioxidant capacities showed a drastic decrease, indicating a faster degradation of the AOX compounds present in all oleoresins (accelerated oxidation temperature). The stability of carotenoids in the oleoresins, per se, is a function of storage conditions. Higher temperatures exert a strong influence on the kinetics of degradation, accelerating the rate of pigment decomposition, which is related as well with reaction rates (Table 3 ).

Itis well established that carotenoids are susceptible to oxidation when exposed to light, oxygen and enzymes; this oxidation could be important in chili and paprika powder storage under room temperatures both in light or darkness conditions (Namitha and Negi, 2010) and their presence as a result of their addition in cold-pressed oils can protect them from lipid oxidation (Alavi and Golmakani, 2017).

In the present research, at the end of the storage, different grades of degradation in the total carotenoid content loss (\%) in both oleoresins were found (Figure 1), being notably higher under the most thermo-degrading conditions $\left(45^{\circ} \mathrm{C}\right)$. A similar behavior was observed in total phenolic compound degradation. The degradation of both antioxidant components may influence the total lipid oxidation of the oleoresin expressed in the Totox values (Figure 2).

At the end of the storage time, the Totox values were significantly higher at $45^{\circ} \mathrm{C}$ (which was observed at early storage time from 7 days). This fact suggests the importance of the assessment of tertiary oxidation compounds in the tested oil. Moreover, only for 21 days of storage at $45^{\circ} \mathrm{C}$ could the oleoresin not be acceptable for its consumption at the highest temperature tested (Totox $>30$ ) (Sun-Waterhouse et al., 2011b). Nonetheless, the oil degradation was not perceptible when preserved at room conditions, which suggests that it can be stored for more than a month without further organoleptic and/or nutritional modifications and without the addition of artificial antioxidants.

However, differences in the carotenoid degradation between both oleoresins were not statistically significant $(\mathrm{P}=0.570)$. The total carotenoid degradation is a big quality problem in paprika and chili powder because it is strongly related with color loss; the addition of other antioxidant molecules (such as tocopherols or BHT) is recommended (Koncsek et al., 2016). Moreover, in avocado oil the natural presence of tocopherols acts as a natural antioxidant (Berasategui et al., 2012). Meanwhile, in chili oleoresins microencapsulation has been used to reduce carotenoid loss during storage (Guadararrama-Lezama et al., 2014), although the carotenoid loss presented here is similar to those encapsulated chili extracts (Dominguez-Cañedo et al., 2015).
The carotenoid loss in both Capsicum oleoresins assayed depended on the initial carotenoid concentration and the temperature applied during storage. The values obtained indicated that the addition of Chipotle chili clearly increases the antioxidant activity per se, reducing the peroxide formation during storage in avocado oil.

Phenolic compounds are bioactive metabolites that might mitigate the oxidative damage and the risk of chronic diseases due to their ability to reduce free radical formation and to scavenge free radicals (González-Gallego et al., 2010). However, due to its polar nature just a small amount was extracted in avocado oil in spite of being of great importance and present in the avocado pulp (Di Stefano et al., 2017). Phenolic degradation was total in AO at 25 and $45^{\circ} \mathrm{C}$ at the end of storage time, similarly to previously reported studies (Sun-Waterhouse et al., 2011). The presence of capsicum oleoresin showed a protective effect, resulting in a reduction in the phenolic loss dependent on the capsicum concentration probably for the carotenoid protective effect in the oxidation process.

\subsection{Color changes during storage}

Total color difference and chroma are considered the most sensitive parameters for the measurement of color degradation in some foods in response to storage under different temperature conditions (Pathare et al., 2013). The total color differences and Chroma during storage at different temperatures of both oleoresins and avocado oil are shown in Figure 3. The avocado oil exhibited significant differences $(p \leq 0.05)$ in color from both oleoresins. These changes may be due to lipidoxidation during storage as the cold-pressed avocado oil used did not have antioxidants as additives in its composition. While the avocado oil showed a slightly greenish color both Chipotle extracts were reddish (see Table 1). Moreover, ground Chipotle chili showed red and blue color components (see Table1). The color of Capsicum oleoresins are clearly related with their carotenoid fraction, composed of more than 50 molecules identified and their loss during storage is an important quality issue although studies about the color stability in capsicum oleoresins are limited (Amruthraj et al., 2014). No Pearson correlation could be found in the present research between total carotenoid degradation and total color changes $(\mathrm{P}<90 \%)$. Nonetheless, color changes were slightly appreciated at the end of storage time in both oleoresins only when stored at $45^{\circ} \mathrm{C}(\mathrm{AE}>1)$ and could not be perceptible at room temperature, which relates to the quality and stability of both oleoresins under appropriate storage conditions. The color differences suggest the presence of color-protective factors, such as the antioxidants coming from the Chipotle chili carotenoid fraction (Figure 3) which 

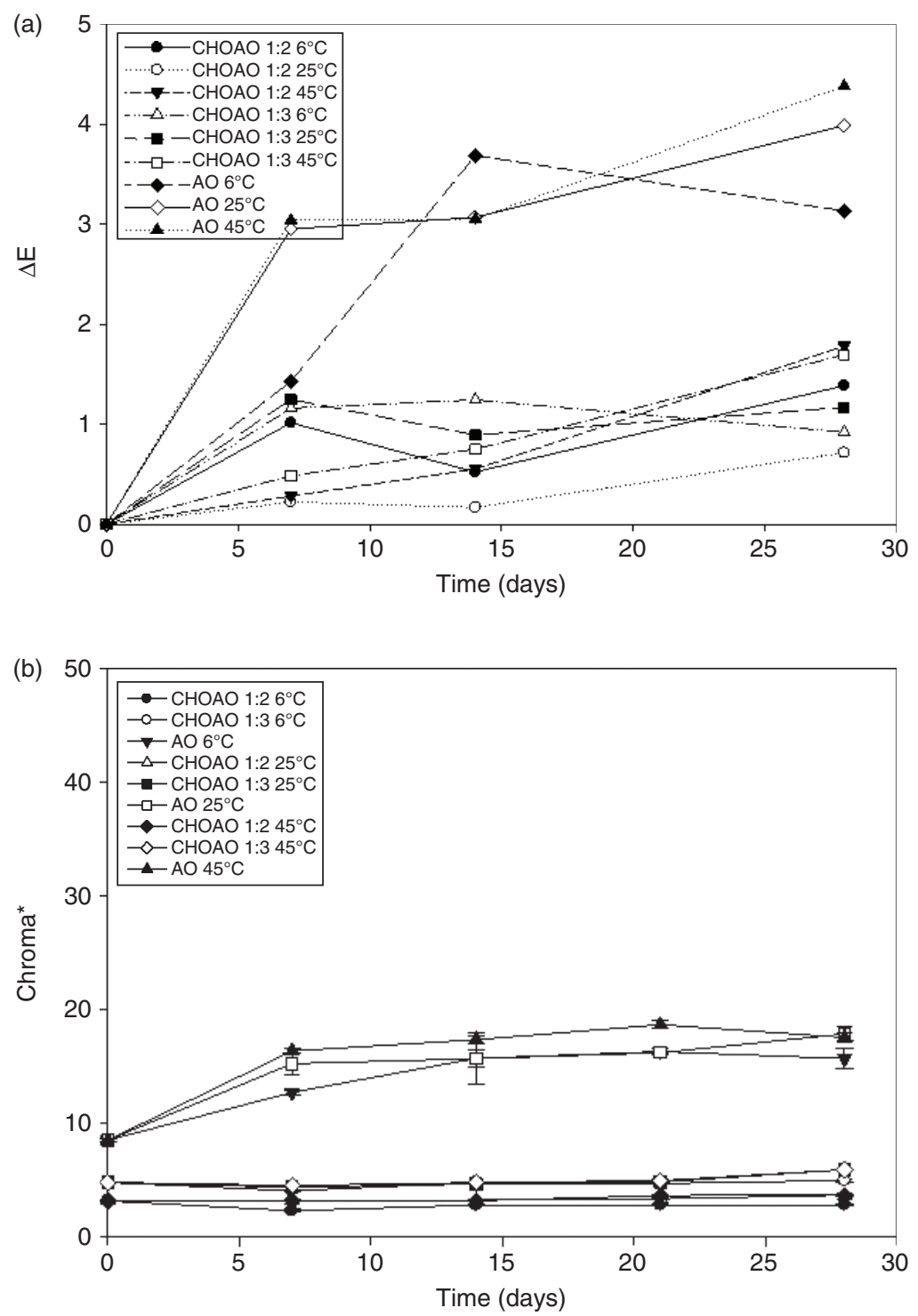

FIGURE 3. Effect of temperature and storage time on a) color changes $(\Delta \mathrm{E})$ and b) Chroma changes in Chipotle oleoresin in avocado oil 1:2 (CHOAO 1:2), Chipotle oleoresin in avocado oil 1:3 (CHOAO 1:3) and avocado oil (AO) during storage.

are partially degraded during the storage time. As storage advanced, the oleoresin samples became less saturated and slightly reddish. Great differences in perceivable color $(\Delta \mathrm{E}>3)$ could be observed in avocado oil at the end of the storage time in all temperatures tested, but was significantly higher at $45^{\circ} \mathrm{C}$. However, for both oleoresins the changes observed at the end of storage (28 days) were not detectable at first sight $(1<\Delta \mathrm{E}>3)$ which indicates that oleoresin may be used as food colorant in foods with short and medium storage times (a month or less). Moreover, in the case of CHOAO 1:2 stored at 25 ${ }^{\circ} \mathrm{C}$ no color changes were detected $(\Delta \mathrm{E}<1)$. Longer storage studies should be performed to appreciate noticeable color changes and determine their shelflife as a colorant.

\subsection{Kinetics}

Kinetic parameters for carotenoid degradation and peroxide formation are shown in Table 3. The carotenoid degradation and peroxide formation data corresponded to a first-order kinetic model, with 0.927 being the smallest value for the linear regression coefficients $\left(\mathrm{R}^{2}\right)$ and these are related to oxidative stability. As Table 3 shows, the higher the temperature, the higher the kinetic constant $(k)$ and, therefore the faster the carotenoid degradation and peroxide formation. As previously mentioned, the total peroxides during storage increased with time, mainly at $45^{\circ} \mathrm{C}$ and were higher in avocado oil than in both oleoresins (Table 2). For total carotenoid degradation, the activation energy $(\mathrm{Ea})$ in $\mathrm{CHOAO}$ 
1:2 was lower than in CHOAO 1:3, but for the peroxide formation the Ea variation may be considered minimal (see Table 3).

Comparing the results with those previously reported is somewhat difficult since different conditions are involved. However, Ea values were lower than previously reported for carotene degradation (Hidalgo et al., 2008). The degradation is mediated at lower temperatures by the $\mathrm{Ea}$, but as the temperature rises, the degradation reaction is controlled by the particle collisions found $\left(K_{0}\right)$. In the case of peroxide formation, Piedrahita et al., 2015 observed that when natural antioxidants were added to choibá oil, the Ea was higher than in the control without natural antioxidants, indicating that this addition reduced the oxidation rate and increased the lifetime of the product.

The kinetic constants are higher for peroxide formation than for carotenoid degradation (Table 3). The high increase in the number of collisions between molecules more than the slight change in the activation energy is the main factor. The frequency factor $K_{0}$ is an entropic factor which indicates the number of collisions that the reactant molecules suffer. Hence, in a reaction controlled by the enthalpy, the changes in the activation energy are proportionally bigger than the changes in the frequency factor. Additionally, in reactions controlled by the entropy, changes in the frequency factor are bigger than changes in the activation energy; in this case the reaction rate might be benefited from a change that may cause a bigger number of collisions of the reactant molecules. Hence, an entropic control implies that the frequency factor is the kinetic parameter that influences the most, instead of the activation energy as in the enthalpic control (Aguilar et al., 2016).

\section{CONCLUSIONS}

The maceration of Chipotle chili (C. annuum L.) in cold-pressed avocado oil could be considered as an economic and green solvent alternative to extract carotenoids with good oxidation stability under normal conditions. The most efficient conditions obtained were a $1: 3(\mathrm{w} / \mathrm{v})$ ratio between chipotle chili and avocado oil, although the most concentrated oleoresin resulted was CHOAO 1:2. The extract obtained was stable against lipid oxidation during storage at room temperature as well as under refrigeration, although lipid oxidation was of importance at the end of the harshest conditions tested $\left(45^{\circ} \mathrm{C}\right)$. Moreover, Chipotle oleoresins showed a relatively high antioxidant activity, which is preserved at 6 and $25^{\circ} \mathrm{C}$. An appropriate storage under room temperature $\left(\leq 25^{\circ} \mathrm{C}\right)$ could be essential to conserve the oleoresin obtained for long time periods with a minimal loss in their functional and bioactive properties.
Thus, both oleoresins may be considered as natural additives. However, studies regarding their application in food products should be carried out to validate this fact, mainly because in foodstuffs the oleoresins will be diluted and interact with other food components. Furthermore, the influence of cooking temperatures in the antioxidant properties of the oleoresins should be completed to have a more comprehensive understanding of the protective effect of these bioactive compounds present before, during and after processing for different food products.

\section{ACKNOWLEDGMENTS}

This work was supported by the Consejo Nacional de Ciencia y Tecnología (Conacyt) through a Masters grant to Liesel Cerecedo.

\section{REFERENCES}

Aguilar K, Garvínn A, Azuara E, Ibarz A. 2016. RateControlling Mechanisms in the Photo- degradation of 5-Hydroxymethylfurfural. Food and Bioprocess Tech. 9, 1399-1407. https://doi.org/10.1007/s11947-016-1729-7

Akbas E, Soyler UB, Oztop MH. 2017. Capsaicin emulsions: Formulation and characterization. J. Dispers. Sci. Technol. 38, 1079-1086. https://doi.org/10.1080/01932691.2016.122 4717

Alavi N, Golmakani MT. 2017. Improving oxidative stability of olive oil: Incorporation of Spirulina and evaluation of its synergism with citric acid. Grasas Aceites 68, e178. https:// doi.org/10.3989/gya.0940162

Amruthraj NJ, Preetam-Raj JP, Antoine Lebel L. 2014. Comparative study on the extraction of capsaicinoids from Capsicum chinese and their analysis by phosphomolybdic acid reduction and HPLC. Int. J. Pharm. Sci. Rev. Res. 28, $247-252$.

American Oil Chemists' Society, Firestone. 1999. Official method and recommended practices of the American Oil Chemists' Society. Methods Cd 8-53. AOCS press. Champaign. Illinois. USA.

Asnin L, Park SW. 2015. Isolation and Analysis of Bioactive Compounds in Capsicum Peppers. Crit. Rev. Food Sci. Nutr. 55, 254-289. https://doi.org/10.1080/10408398.2011. 652316

Barros HDFQ, Coutinho JP, Grimaldi R, Godoy HT, Cabral FA. 2016. Simultaneous extraction of edible oil from avocado and capsanthin from red bell pepper using supercritical carbon dioxide as solvent. J. Supercrit. Fluids $\mathbf{1 7 0}$, 315-320. https://doi.org/10.1016/j.supflu.2015.09.025

Bearth A, Cousin ME, Siegrist M. 2014. The consumer's perception of artificial food additives: Influences on acceptance, risk and benefit perceptions. Food Qual. Prefer. 38, 14-23. https://doi.org/10.1016/j.foodqual.2014.05.008

Benzie IFF, Strain JJ. 1996. The Ferric Reducing Ability of Plasma (FRAP) as a Measure of Antioxidant Power: The FRAP Assay. Anal. Biochem. 239, 70-76. https://doi. org/10.1006/abio.1996.0292

Berasategi I, Barriuso B, Ansorena D, Astiasarán I. 2012. Stability of avocado oil during heating: Comparative study to olive oil. Food Chem. 132, 439-446. https://doi. org/10.1016/j.foodchem.2011.11.018

Cavazza A, Corti S, Mancinelli C, Bignardi C, Corradini C. 2015. Effect of the Addition of Chili Pepper Powder on Vegetable Oils Oxidative Stability. J. Am. Oil Chem. Soc. 92, 1593-1599. https://doi.org/10.1007/s11746-015-2738-9

Domínguez-Cañedo IL, Beristain-Guevara CI, Díaz-Sobac R, Vázquez-Luna, A. 2015. Degradación de carotenoides y capsaicina en el complejo de inclusión molecular de 
oleorresina de chile habanero (Capsicum chinense) con $\beta$-ciclodextrina. CyTA - J. Food 13, 151-158. https://doi.org $/ 10.1080 / 19476337.2014 .926459$

Espinosa-Alonso LG, Paredes-López O, Valdez-Morales M, Oomah BD. 2017. Avocado oil characteristics of Mexican creole genotypes. Eur. J. Lipid Sci. Technol. 119, 1-12. https://doi.org/10.1002/ejlt.201600406

Gómez-Moriel CB., Quintero-Ramos A, Camacho-Dávila A, Ruiz-Gutiérrez MG, Talamás-Abbud R, Olivas-Vargas R, Barnard J. 2012. Optimization of chipotle pepper smoking process using response surface methodology. J. Food Qual. 35, 21-33. https://doi.org/10.1111/j.1745-4557.2011.00428.x

González-Gallego J, García-Mediavilla MV, Sánchez-Campos S, Tuñón MJ. 2010. Fruit polyphenols, immunity and inflammation. Br. J. Nutr. 104, S15-S27. https://doi.org/10.1017/ S0007114510003910

Goula AM, Ververi M, Adamopoulou A, Kaderides K. 2017. Green ultrasound-assisted extraction of carotenoids from pomegranate wastes using vegetable oils. Ultrason. Sonochem. 34, 821-83. https://doi.org/10.1016/j. ultsonch.2016.07.022

Guadarrama-Lezama AY, Dorantes-Alvarez L, JaramilloFlores ME, Pérez-Alonso C, Niranjan K, Gutiérrez-López GF, Alamilla-Beltrán L. 2012. Preparation and characterization of non-aqueous extracts from chilli (Capsicum anпиит $\mathrm{L}$.) and their microencapsulates obtained by spraydrying. J. Food Eng. 112, 29-37. https://doi.org/10.1016/j. jfoodeng.2012.03.032

Guadarrama-Lezama AY, Jaramillo-Flores E, Gutiérrez-López GF, Pérez-Alonso C, Dorantes-Alvarez L, AlamillaBeltrán L. 2014. Effects of Storage Temperature and Water Activity on the Degradation of Carotenoids Contained in Microencapsulated Chili Extract. Dry. Technol. 32, 14351447. https://doi.org/10.1080/07373937.2014.900502

Güneșer BA, Yilmaz E, Ok S. 2017. Cold pressed versus refined winterized corn oils: quality, composition and aroma. Grasas Aceites 68, 1-12. https://doi.org/10.3989/gya.1168162

Hidalgo A, Brandolini A. 2008. Kinetics of Carotenoids Degradation during the Storage of Einkorn (Triticummonococcum L. ssp. monococcum) and Bread Wheat (Triticumaestivum L. ssp. aestivum) Flours. J. Agric. Food Chem. 56, 11300-11305. https://doi.org/10.1021/jf802448t

Hornero-Méndez D, Mínguez-Mosquera MI. 2001. Rapid Spectrophotometric Determination of Red and Yellow Isochromic Carotenoid Fractions in Paprika and Red Pepper Oleoresins. J. Agric. Food Chem. 49, 3584-3588. https://doi.org/10.1021/jf0104001

Kittisakulnam S, Saetae D, Suntornsuk W. 2016. Antioxidant and Antibacterial Activities of Spices Traditionally Used in Fermented Meat Products. J. Food Process. Preserv. 41, 1-8. https://doi.org/10.1111/jfpp.13004

Koncsek A, Kruppai L, Helyes L, Bori Z, Daood HG. 2016. Storage Stability of Carotenoids in Paprika from Conventional, Organic and Frost-Damaged Spice Red Peppers as Influenced by Illumination and Antioxidant Supplementation. J. Food Process. Preserv. 40, 453-462. https://doi.org/10.1111/jfpp.12623

Kovács A, Erős I, Csóka I. 2016. Optimization and development of stable w/o/w cosmetic multiple emulsions by means of the Quality by Design approach. Int. J. Cosmet. Sci. 38, 128-138. https://doi.org/10.1111/ICS.12248

Melgar-Lalanne G, Hernández-Álvarez AJ, Jiménez-Fernández M, Azuara E. 2017. Oleoresins from Capsicum spp.: Extraction Methods and Bioactivity. Food Bioprocess Technol. 10, 51-76. https://doi.org/10.1007/s11947-016-1793-z

Moon JK, Shibamoto T. 2009. Antioxidant Assays for Plant and Food Components. J. Agric. Food Chem. 57, 1655-1666. https://doi.org/10.1021/jf803537k

Namitha KK, Negi PS. 2010. Chemistry and Biotechnology of Carotenoids. Crit. Rev. Food Sci. Nutr. 50, 728-760. https:// doi.org/10.1080/10408398.2010.499811

Pathare PB, Opara UL, Al-Said FAJ. 2013. Colour Measurement and Analysis in Fresh and Processed Foods: A Review.
Food Bioprocess Technol. 6, 36-60. https://doi.org/10.1007/ s11947-012-0867-9

Piedrahita AM, Peñaloza J, Cogollo Á, Rojano BA. 2015. Kinetic study of the oxidative degradation of choibá oil (Dipteryx oleifera Benth.) with addition of rosemary extract (Rosmarinus officinalis L.). FNS 6, 466479. https:// doi.org/10.4236/fns.2015.65048

Prescha A, Grajzer M, Dedyk M, Grajeta H. 2014. The Antioxidant Activity and Oxidative Stability of ColdPressed Oils. J. Am. Oil Chem. Soc. 91, 1291-1301. https:// doi.org/10.1007/s11746-014-2479-1

Qin X, Zhong J. 2016. A Review of Extraction Techniques for Avocado Oil. J. Oleo Sci. 65, 881-888. https://doi. org $/ 10.5650 /$ jos.ess 16063

Rege SA, Momin SA. 2017. Synergistic Antioxidant Activity of Capsicum Oleoresin, Lecithin and Curcuminoids in Sunflower Oil. Int. J. Food. Process. Technol. 4, 6-11. https://doi.org/10.15379/2408-9826.2017.04.01.02

Sachindra NM, Mahendrakar NS. 2005. Process optimization for extraction of carotenoids from shrimp waste with vegetable oils. Bioresour. Technol. 96, 1195-1200. https://doi. org/10.1016/j.biortech.2004.09.018

Salazar R, Arámbula-Villa G, Hidalgo FJ, Zamora R. 2012. Mitigating effect of piquin pepper (Capsicum annuиm $\mathrm{L}$. var. Aviculare) oleoresin on acrylamide formation in potato and tortilla chips. LWT - Food Sci. Technol. 48, 261-267. https://doi.org/10.1016/j.lwt.2012.03.024

Shahidi F, Wanasundara UN. 2003. Methods for measuring oxidative rancidity in fats and oils. In: Akoh, C.C. (Ed.), Food Lipids-chemistry, Nutrition, and Biotechnology. Marcel Dekker, Inc., New York, USA, 465-487. https:// doi.org/10.1002/ejlt.200390077

Shahidi F, Zhong Y. 2015. Measurement of antioxidant activity. J. Funct. Foods. 18, 757-781. https://doi.org/10.1016/j. jff. 2015.01 .047

Sousa A, Casal S, Malheiro R, Lamas H, Bento A, Pereira JAJA. 2015. Aromatized olive oils: Influence of flavouring in quality, composition, stability, antioxidants and antiradical potential. LWT - Food Sci. Technol. 60, 22-28. https:// doi.org/10.1016/j.lwt.2014.08.026

Sun-Waterhouse D, Thakorlal J, Zhou J. 2011. Effects of added phenolics on the storage stability of avocado and coconut oils. Int. J. Food Sci. Technol. 46, 1575-1585. https://doi. org/10.1111/j.1365-2621.2011.02655.x

Sun-Waterhouse D, Zhou J, Miskelly GM, Wibisono R, Wadhwa SS. 2011. Stability of encapsulated olive oil in the presence of caffeic acid. Food Chem. 126, 1049-1056. https://doi. org/10.1016/j.foodchem.2010.11.124

Unlu NZ, Bohn T, Clinton SK, Schwartz SJ. 2005. Carotenoid absorption from salad and salsa by humans is enhanced by the addition of avocado or avocado oil. J. Nutr. $\mathbf{1 3 5}$, 431-436.

Vaisali C, Belur PD, Regupathi I. 2016. Comparison of antioxidant properties of phenolic compounds and their effectiveness in imparting oxidative stability to sardine oil during storage. LWT - Food Sci. Technol. 69, 153-160. https://doi. org/10.1016/j.lwt.2016.01.041

Victoria-Campos CI, Ornelas-Paz JJ, Yahia EM, Failla ML. 2013. Effect of the Interaction of Heat-Processing Style and Fat Type on the Micellarization of Lipid-Soluble Pigments from Green and Red Pungent Peppers (Capsicum annuum). J. Agric. Food Chem. 61, 3642-3653. https://doi. org/10.1021/jf3054559

Vikram VB, Ramesh MN, Prapulla SG 2005. Thermal degradation kinetics of nutrients in orange juice heated by electromagnetic and conventional methods. J. Food Eng. 69, 31-40. https://doi.org/10.1016/j. jfoodeng.2004.07.013

Wong M, Ashton OBO, McGhie TK, Requejo-Jackman C, Wang Y, Woolf AB. 2011. Influence of Proportion of Skin Present During Malaxing on Pigment Composition of Cold Pressed Avocado Oil. J. Am. Oil Chem. Soc. 88, 1373-1378. https://doi.org/10.1007/s11746-011-1790-3 